
ra 24: 301-304.

\title{
Metodologia para a avaliação do vigor de sementes de tomate
}

\author{
Cibele C Martins; Márcia Maria Castro; Adriana M Seneme; João Nakagawa \\ UNESP-FCA-Dep ${ }^{\text {to. }}$ Produção Vegetal, C. Postal 237, 18603-970 Botucatu-SP; E-mail: cibele@fca.unesp.br; marciacastro@fca.unesp.br
}

\section{RESUMO}

Os testes de vigor e o teste de germinação são componentes essenciais no controle de qualidade das empresas de produção de sementes. Com o objetivo de verificar a eficiência de diferentes testes de vigor na avaliação da qualidade de sementes de tomate (Lycopersicon esculentum Mill), cinco lotes do híbrido Saladinha foram submetidos aos seguintes testes: germinação; primeira contagem de germinação; emissão de raiz (56, 72, 80 e 96 horas após a instalação do teste de germinação); emergência de plântulas (substrato em bandejas de poliestireno); envelhecimento acelerado ( $1 \mathrm{~g}$ de sementes mantidas a $41^{\circ} \mathrm{C}$ por 48 e 72 horas); envelhecimento acelerado com solução salina saturada (mesmo procedimento do item anterior mas usando solução de $\mathrm{NaCl}, 40 \%$ ) e condutividade elétrica (50 sementes em $25 \mathrm{~mL}$ de água destilada) em câmara a $25^{\circ} \mathrm{C}$ e leituras após 2, 4, 6, 8 e 24 horas. A porcentagem de germinação e os testes de vigor da emissão de raiz primária (após 56 e 72 horas) e de condutividade elétrica apresentaram-se correlacionados com a emergência de plântulas. Porém, somente o teste de condutividade elétrica após 24 horas de embebição mostrou-se eficiente na avaliação do vigor das sementes de tomate, fornecendo informações semelhantes à emergência de plântulas.

Palavras-chave: Lycopersicon esculentum Mill, controle de qualidade, condutividade elétrica, envelhecimento acelerado, olerícolas.

\section{ABSTRACT}

\section{Methodology for the evaluation of tomato seed vigor}

The vigor and germination tests are essential components of seed quality control for the seed industry. In this research an adequate method to estimate vigor of different tomato seed lots was studied. Five lots of tomato seeds of 'Saladinha' hybrid were submitted to the following tests: germination; first counting of germination; root emission (56, 72, 80, and 96 hours after sowing); seedling emergence on spedling trays; accelerated aging with water $(1 \mathrm{~g}$ of seeds maintained at $41^{\circ} \mathrm{C}$ during 48 and 72 hours); accelerated aging with salt (the same procedure of last item, but using $40 \% \mathrm{NaCl}$ solution); electrical conductivity ( 50 seeds in $25 \mathrm{~mL}$ of distillated water at 25 ${ }^{\circ} \mathrm{C}$ and evaluations after 2, 4, 6, 8, and 24 hours of imbibition). The germination percentage and vigor tests of primary root emission (after 56 and 72 hours) and electrical conductivity were correlated with seedling emergence. However, only the electrical conductivity test after 24 hours of imbibition showed efficiency to evaluate vigor of tomato seeds taking similar information to seedling emergence.

Keywords: Lycopersicon esculentum Mill, quality control, electrical conductivity, accelerated aging, vegetables.

\section{(Recebido para publicação em 28 de fevereiro de 2005; aceito em 24 de agosto de 2006)}

A qualidade das sementes é de grande importância na aceitação de um híbrido no mercado e a avaliação do vigor de sementes é um componente essencial do programa de controle de qualidade, adotado pela indústria sementeira. Deste modo, os testes de vigor disponíveis vêm sendo aperfeiçoados, adaptando-os às diferentes espécies, para permitir a obtenção de resultados consistentes e reproduzíveis. Alguns testes de vigor podem ser realizados conjuntamente com o teste de germinação. A primeira contagem de germinação, realizada para facilitar a condução do teste de germinação, pode ser considerada um teste de vigor, pois sabe-se que no processo de deterioração a velocidade da germinação é um dos primeiros parâmetros a ser afetado (Carvalho, 1994). Utilizando o mesmo princípio, pode-se avaliar o vigor de um lote pelo índice de velocidade de emergência ou pela precocidade da emissão da raiz primária, com grande eficiência, como foi observado, por exemplo, para sementes de milho (Salgado, 1996) e de brócolis (Martins et al., 2002).

Outro teste rápido de vigor, o da condutividade elétrica, avalia indiretamente a qualidade das sementes, baseado na concentração de eletrólitos lixiviados pelas sementes durante o período de embebição, fornecendo resultados no prazo máximo de 24 horas (Vieira, 1994). Para sementes de tomate, o tempo de embebição para esse teste pode variar de quatro (Sá, 1999) a seis horas (Rodo et al., 1998) e a eficiência da metodologia do teste pode depender da cultivar a ser avaliada (Rodo et al., 1998).

Um dos testes mais utilizados para a avaliação do vigor é o envelhecimento acelerado (Marcos Filho, 1999a), que se baseia no aumento da deterioração das sementes expostas à alta temperatura e umidade relativa. Ensaios de aprimoramento da metodologia do envelhecimento acelerado para olerícolas têm sido implementados, testando-se diferentes temperaturas e tempos de exposição das sementes ao estresse e comparando-se os resultados à emergência de plântulas em campo e a outros testes de vigor, tendo-se obtido para tomate as recomendações de 72 horas de exposição a $41^{\circ} \mathrm{C}$ (Hampton \& TeKrony, 1995) ou $42^{\circ} \mathrm{C}$ (Nascimento et al., 1993). Por outro lado, métodos alternativos para o teste de envelhecimento acelerado em espécies de sementes pequenas, como é o caso das hortaliças, vêm sendo estudados, como a substituição da água por soluções saturadas de sais (Panobianco \& Marcos Filho, 1998; Rodo et al., 2000; Martins et al., 2002). Dependendo da solução utilizada, são obtidos níveis específicos de umidade relativa do ambiente, permitindo adequar a taxa de absorção de água da semente, a velocidade e a intensidade de deterioração da mesma. Assim, para sementes de olerícolas, como pimentão (Panobianco \& Marcos Filho, 1998), cenoura (Rodo 
Tabela 1. Coeficientes de correlação simples (R) entre os testes de laboratório e a emergência de plântulas em substrato para mudas, para as sementes de cinco lotes de tomate. Botucatu, UNESP, 2001.

\begin{tabular}{|c|c|}
\hline Testes de laboratório $X$ emergência de plântulas & $\mathbf{R}$ \\
\hline Germinação & $0,575^{* *}$ \\
\hline Primeira contagem & $0,061^{\text {ns }}$ \\
\hline Emissão de raiz primária após 56 horas & $0,461^{*}$ \\
\hline após 72 horas & $0,531^{*}$ \\
\hline após 80 horas & 0,319 ns \\
\hline após 96 horas & $0,135^{\mathrm{ns}}$ \\
\hline Envelhecimento acelerado após 48 horas & $-0,132 \mathrm{~ns}$ \\
\hline após 72 horas & $-0,110$ ns \\
\hline Envelhecimento acelerado em solução salina após 48 horas & $-0,085^{\mathrm{ns}}$ \\
\hline após 72 horas & $-0,163^{\text {ns }}$ \\
\hline Condutividade elétrica após 2 horas & $-0,700^{* * *}$ \\
\hline após 4 horas & $-0,749^{* * *}$ \\
\hline após 6 horas & $-0,769 * * *$ \\
\hline após 8 horas & $-0,859^{* * *}$ \\
\hline após 24 horas & $-0,589^{* *}$ \\
\hline
\end{tabular}

Significativo a $5 \%(*), 1 \%(* *)$ e $0,1 \%(* * *)$ de probabilidade.

et al., 2000) e brócolis (Martins et al., 2002), o teste de envelhecimento acelerado $\left(41^{\circ} \mathrm{C}\right.$ por $\left.72 \mathrm{~h}\right)$ com o uso de solução saturada de $\mathrm{NaCl}$ tem apresentado maior eficiência na detecção de diferenças de qualidade de lotes que o envelhecimento acelerado sem o uso do sal.

O presente trabalho foi conduzido com o objetivo de verificar a eficiência de diferentes testes de vigor e de variações em suas metodologias na avaliação da qualidade de sementes de tomate (Lycopersicon esculentum Mill), visando a diferenciação de lotes e previsão de emergência de plântulas.

\section{MATERIAL E MÉTODOS}

O trabalho foi conduzido em laboratório da UNESP em Botucatu, SP, com sementes de tomate híbrido Saladinha (Sakata, 2002). Foram avaliados cinco lotes, colhidos nos seguintes locais e anos: Lotes 1 e 2 - 1998, em Joanópolis, SP; Lote 3 - 2001, em Atibaia, SP; Lotes 4 e 5 - 1998, em Cambuí, MG. As sementes foram armazenadas em câmara com $20^{\circ} \mathrm{C}$ de temperatura e $33 \%$ de umidade relativa do ar até a realização do estudo em 2001.

Foram conduzidos os seguintes testes para avaliar a qualidade de sementes: germinação - realizado com quatro subamostras de 50 sementes, semeadas sobre duas folhas de papel mata-borrão umedecidas com 2,5 vezes o peso do papel em água, em caixas plásticas transparentes $(11 \times 11 \times 3,5 \mathrm{~cm})$ em temperaturas alternadas de $20^{\circ} \mathrm{C}$ por 16 horas no escuro e $30^{\circ} \mathrm{C}$ por 8 horas na luz (Brasil, 1992). As contagens das plântulas normais foram efetuadas no quinto e no $10^{\circ}$ dia (Brasil, 1992); primeira contagem de germinação - realizada conjuntamente com o teste de germinação, contabilizando-se as plântulas normais presentes no quinto dia após a semeadura; precocidade de emissão de raiz primária - realizada juntamente com o teste de germinação contabilizando-se o número de sementes que emitiram a raiz primária após $56,72,80$ e 96 horas da semeadura (contagem diária sempre no início e final do período da temperatura mais alta do teste de germinação); emergência de plântulas - utilizando-se quatro repetições de 100 sementes por lote, semeando-se duas sementes por célula em bandejas de poliestireno, a $0,5 \mathrm{~cm}$ de profundidade, em substrato próprio para produção de mudas de olerícolas (Plantmax), umedecido duas vezes ao dia e conduzido em túnel plástico. Aos 14 dias, foi realizada a contagem de plântulas normais emersas. A umidade relativa do ar e temperatura do ambiente durante esse período foram registradas pelo termohigrômetro; envelhecimento acelerado - conduzido com $1 \mathrm{~g}$ de sementes sobre tela em caixa plástica tipo gerbox contendo $40 \mathrm{~mL}$ de água, mantidas a $41^{\circ} \mathrm{C}(100 \%$ UR) por 48 e 72 horas (Hampton \& TeKrony, 1995; Panobianco \& Marcos Filho, 1998), seguindo-se da avaliação da germinação com o mesmo procedimento do teste de germinação com contagem no quinto dia; envelhecimento acelerado com solução salina saturada - utilizouse o mesmo procedimento do item anterior, porém a água foi substituída por uma solução saturada de $\mathrm{NaCl}(40 \%)$, com o uso do sobrenadante, de modo a obter um ambiente com $76 \%$ de UR do ar, adaptando-se a metodologia utilizada por Jianhua \& McDonald (1996); Panobianco \& Marcos Filho (1998) e Rodo et al. (2000); condutividade elétrica - foram utilizadas quatro subamostras de 50 sementes por lote, pesadas em balança com precisão de $0,001 \mathrm{~g}$ e colocadas para embeber em copos plásticos contendo $25 \mathrm{~mL}$ de água destilada à temperatura de $25^{\circ} \mathrm{C}$, sendo que as leituras foram efetuadas após 2 , 4, 6, 8 e 24 horas (Vieira, 1994).

Além da determinação da qualidade fisiológica, determinou-se também o teor de água das sementes, antes e após o teste de envelhecimento acelerado com água e com solução salina saturada, utilizando-se duas subamostras para cada lote e adotando-se o método da estufa a $105 \pm 3^{\circ} \mathrm{C} / 24 \mathrm{~h}$ (Brasil, 1992).

A análise de variância foi realizada separadamente para cada teste, em delineamento inteiramente casualizado, com quatro repetições, onde a comparação entre as médias dos lotes foi efetuada pelo teste de Tukey, ao nível de $5 \%$ de probabilidade. Os dados expressos em porcentagem foram transformados em arc sen $(\mathrm{x} / 100)^{1 / 2}$ e quando ocorreu valor igual a zero, os dados em porcentagem foram transformados em $(x+0,5)^{1 / 2}$. Realizou-se a determinação dos coeficientes de correlação simples entre os resultados dos testes de laboratório e da emergência de plântulas.

\section{RESULTADOS E DISCUSSÃO}

Os testes de primeira contagem, emissão de raiz primária, após 80 e 96 horas e envelhecimento acelerado com e sem sal não apresentaram correlação 
com a emergência de plântulas e, por isso, não foram considerados na análise de qualidade dos lotes. Contrariamente, a porcentagem de germinação e os testes de vigor da emissão de raiz primária, após 56 e 72 horas e de condutividade elétrica foram parâmetros altamente correlacionados com a emergência de plântulas, podendo ser considerados promissores na avaliação da qualidade de sementes de tomateiro (Tabela 1).

Os resultados de correlação simples entre condutividade elétrica e emergência de plântulas (Tabela 1) indicaram correlação negativa entre os testes. Isto significa que aumentos nos valores de condutividade elétrica corresponderam a queda nos níveis de emergência de plântulas (vigor da sementes) e, este fato, concorda com relatos da literatura, onde os aumentos nos índices de condutividade elétrica corresponderam à maior lixiviação de solutos e, portanto, à diminuição na qualidade fisiológica das sementes (McDonald \& Wilson, 1979; Powell, 1986 e Marcos Filho et al., 1990).

$\mathrm{Na}$ avaliação da qualidade das sementes, as médias dos lotes foram comparadas (Tabela 2), para se obter maior precisão na eficiência dos testes cuja correlação foi significativa, permitindo classificar o desempenho dos lotes em ordem decrescente de vigor dos lotes de 1 a 5 .

O teste de germinação não foi capaz de detectar as diferenças de vigor entre os lotes. Isso é verificado com frequiência na rotina dos laboratórios de sementes, visto que este teste é necessariamente conduzido em condições consideradas ideais para a espécie e, por isso, não detecta pequenas variações de vigor (Marcos Filho, 1999b).

A emergência de plântulas em substrato em bandeja foi o teste usado como referência na comparação com os demais testes de vigor. Durante o período de condução do teste, o ambiente do túnel plástico apresentou temperaturas de $27 \pm 9^{\circ} \mathrm{C}$ e umidades relativas de $68 \pm 29 \%$. Este teste foi capaz de separar os lotes em três classes de vigor: alto (lotes $1,2 \mathrm{e}$ 3), médio (lote 4 ) e baixo (5).

Os testes de emissão de raiz primária apresentaram resultados contraditó-
Tabela 2. Resultados dos testes de germinação $(\mathrm{G})$ e de vigor avaliado pelo teste de emergência de plântulas em substrato para mudas em bandeja (EB), primeira contagem de germinação aos 5 dias após a semeadura (PC), emissão de raiz primária (ER) após 48, 56, 72, 80 e 96 horas, envelhecimento acelerado (EA) e envelhecimento acelerado em solução salina (EAS) por 48 e 72 horas, condutividade elétrica (CE) 2, 4, 6, 8 e 24 horas de sementes de cinco lotes de tomate. Botucatu, UNESP, 2001.

\begin{tabular}{|c|c|c|c|c|c|c|c|c|c|c|c|c|}
\hline \multirow{2}{*}{\multicolumn{2}{|c|}{ Avaliação de qualidade }} & \multicolumn{10}{|c|}{ Lotes* } & \multirow{3}{*}{$\frac{\mathrm{CV}(\%)}{7,12}$} \\
\hline & & \multicolumn{2}{|c|}{1} & \multicolumn{2}{|c|}{2} & \multicolumn{2}{|c|}{3} & \multicolumn{2}{|c|}{4} & \multicolumn{2}{|c|}{5} & \\
\hline $\mathrm{G}(\%)$ & & 91 & $A$ & 82 & $A$ & 82 & $A$ & 83 & $A$ & 80 & $A$ & \\
\hline $\mathrm{E} \mathrm{B}(\%)$ & & 96 & $A$ & 97 & $A$ & 94 & $A$ & 76 & $B$ & 59 & C & 4,26 \\
\hline PC (\%) & & 42 & $A$ & 1 & $B$ & 37 & $A$ & 0 & $B$ & 26 & $A$ & 22,82 \\
\hline \multirow[t]{4}{*}{ ER (\%) } & $56 \mathrm{~h}$ & 29 & $A$ & 2 & $C D$ & 5 & $\mathrm{BC}$ & 0 & $D$ & 8 & B & 20,65 \\
\hline & $72 \mathrm{~h}$ & 52 & $A$ & 17 & $B$ & 17 & $B$ & 6 & $B$ & 19 & B & 26,58 \\
\hline & $80 h$ & 69 & $A$ & 34 & $\mathrm{BC}$ & 45 & $A B$ & 17 & $C$ & 53 & $A B$ & 20,26 \\
\hline & $96 \mathrm{~h}$ & 81 & $A$ & 46 & $\mathrm{BC}$ & 71 & $A B$ & 35 & $C$ & 69 & $A B$ & 13,93 \\
\hline \multirow[t]{2}{*}{ EA (\%) } & $48 h$ & 86 & $A B$ & 12 & $C$ & 94 & $A$ & 11 & $C$ & 76 & B & 9,30 \\
\hline & $72 \mathrm{~h}$ & 81 & $A$ & 9 & $C$ & 63 & $A B$ & 0 & $D$ & 49 & B & 14,23 \\
\hline \multirow[t]{2}{*}{ EAS (\%) } & $48 h$ & 80 & $B$ & 20 & $C$ & 96 & $A$ & 13 & $C$ & 64 & B & 9,98 \\
\hline & $72 \mathrm{~h}$ & 44 & $B$ & 7 & $D$ & 95 & $A$ & 2 & $E$ & 23 & $C$ & 9,59 \\
\hline CE & $2 \mathrm{~h}$ & 230 & $B$ & 216 & $B$ & 240 & B & 387 & $A$ & 404 & $A$ & 3,88 \\
\hline \multirow[t]{4}{*}{$\left(\mu \mathrm{S} \mathrm{cm} \mathrm{cm}^{-1} \mathrm{~g}^{-1}\right)$} & $4 \mathrm{~h}$ & 258 & $\mathrm{C}$ & 241 & C & 289 & $B$ & 416 & $A$ & 429 & A & 4,36 \\
\hline & $6 \mathrm{~h}$ & 298 & $C$ & 285 & C & 338 & B & 456 & $A$ & 454 & $A$ & 4,29 \\
\hline & $8 \mathrm{~h}$ & 323 & $\mathrm{C}$ & 323 & C & 414 & B & 485 & $A$ & 482 & A & 5,25 \\
\hline & $24 \mathrm{~h}$ & 429 & $\mathrm{C}$ & 475 & $\mathrm{BC}$ & 496 & $\mathrm{BC}$ & 562 & $B$ & 730 & $A$ & 8,29 \\
\hline
\end{tabular}

Médias seguidas de mesma letra na linha não diferem entre si pelo teste de Tukey $(\mathrm{P}<0,05)$; As médias apresentadas são dos dados originais. Os dados expressos em porcentagem foram transformados em arc sen $(x / 100)^{1 / 2}$ ou em $(x+0,5)^{1 / 2}$, quando ocorreram valores iguais a zero.* Lotes 1 e 2 colhidos em 1998 em Joanópolis, SP; Lote 3 colhido em 2001, em Atibaia, SP e Lotes 4 e 5 colhidos em 1998, em Cambuí, MG.

rios ou inconsistentes na classificação do vigor dos lotes quando comparados com os resultados do teste de referência (emergência de plântulas), ou com os demais testes de vigor, pois apresentou similaridades entre os lotes 2, 3, 4 e 5, após 56 e 72 horas de embebição.

Ainda na Tabela 2, observa-se que o teste de condutividade elétrica, realizado após 2 horas de embebição, não foi tão eficiente na classificação dos lotes, quando comparado ao teste de referência adotado e ao conjunto dos demais testes, pois classificou os lotes em apenas duas categorias de vigor. Para a condutividade elétrica nos períodos de embebição de 4, 6 e 8 horas, observouse que os lotes 1 e 2 apresentaram os menores valores, podendo então serem classificados como lotes de alto vigor. $\mathrm{O}$ lote 3 apresentou valores intermediários de vigor e os lotes 4 e 5 podem ser considerados como de baixo vigor. Assim, os testes de condutividade elétrica nos períodos de embebição de 2, 4, 6 e 8 horas foram mais rigorosos que o de emergência de plântulas, não permitindo a dife- renciação dos lotes 4 e 5,respectivamente, de médio e baixo vigor, segundo o teste de emergência de plântulas.

Dentre os testes avaliados, o de condutividade elétrica pelo período de 24 horas de embebição foi o que apresentou resultados mais próximos aos de emergência de plântulas quanto à classificação do vigor dos lotes, apresentando três categorias de vigor: alto (lote 1), médio (lote 4) e baixo (lote 5), ficando os lotes 2 e 3 numa categoria intermediária (alto-médio), estatisticamente semelhante aos lotes 1 e 4 . Estes resultados mostram que para o híbrido Saladinha o tempo de embebição necessário para teste da condutividade elétrica é superior ao obtido por Sá (1999) e Rodo et al. (1998), de quatro e seis horas, respectivamente. Assim, o teste de condutividade elétrica após 24 horas de embebição é eficiente na avaliação do vigor das sementes de tomate, fornecendo informações semelhantes à emergência de plântulas em substrato.

Os teores de água inicial das sementes dos lotes estavam próximos (Tabela 3), mas 
Tabela 3. Teor de água inicial e após o teste do envelhecimento acelerado em água (EA) e em solução salina (EAS) por 48 e 72 horas em cinco lotes de sementes de tomate. Botucatu, UNESP, 2001.

\begin{tabular}{lrrrrrr}
\hline \multirow{2}{*}{\multicolumn{2}{l}{ Teor de água (\%) }} & \multicolumn{5}{c}{ Lotes $^{*}$} \\
\cline { 3 - 7 } & \multicolumn{1}{c}{$\mathbf{1}$} & $\mathbf{2}$ & $\mathbf{3}$ & $\mathbf{4}$ & \multicolumn{1}{c}{$\mathbf{5}$} \\
\hline \multicolumn{2}{l}{ Inicial } & 7,7 & 8,0 & 7,7 & 6,1 & 8,8 \\
EA & $48 \mathrm{~h}$ & 21,7 & 33,7 & 33,6 & 40,1 & 41,5 \\
& $72 \mathrm{~h}$ & 22,1 & 45,1 & 35,8 & 47,6 & 46,9 \\
\multirow{2}{*}{ EAS } & $48 \mathrm{~h}$ & 10,0 & 10,3 & 10,3 & 11,8 & 10,3 \\
& $72 \mathrm{~h}$ & 12,0 & 10,6 & 9,4 & 11,0 & 11,3 \\
\hline
\end{tabular}

*Lotes 1 e 2 colhidos em 1998 em Joanópolis, SP; Lote 3 colhido em 2001, em Atibaia, SP e Lotes 4 e 5 colhidos em 1998, em Cambuí, MG.

foram constatadas diferenças para essa característica e este fato pode ter influenciado os resultados do envelhecimento acelerado, atuando sobre a velocidade e a intensidade de deterioração das sementes. O teor de água das sementes, após os testes, foi diferente entre os lotes ( $\mathrm{Ta}$ bela 3), tendo sido mais discrepante para os testes sem sal.

Um dos principais indicadores da uniformidade das condições de envelhecimento acelerado é o teor de água ao final do teste, quando variações entre 3 a 4 pontos percentuais entre as amostras são consideradas toleráveis (Marcos Filho, 1999a); neste estudo, as variações obtidas, muitas vezes, situaram-se acima dos limites toleráveis, o que justifica os resultados insatisfatórios e desqualifica a utilização deste teste para a avaliação do vigor na comparação dos lotes.

Powell (1995), relata que pesquisas conduzidas com espécies de sementes pequenas, como as hortaliças, têm revelado resultados pouco consistentes devido à variação muito acentuada no teor de água das amostras após o envelhecimento. Também, Panobianco \& Marcos Filho (1998), trabalhando com sementes de pimentão, constataram elevação acentuada no teor de água após o envelhecimento acelerado e variações de até 8,3 pontos percentuais entre as amostras. Rodo et al. (2000) e Spínola et al. (1998) verificaram para sementes de cenoura variações de até 9,2 e 7,2 pontos percentuais, respectivamente. Esse é um dos problemas que se procura sanar com a utilização de solução salina no envelhecimento acelerado.

As sementes submetidas ao teste de envelhecimento acelerado modificado (em solução salina saturada de $\mathrm{Na} \mathrm{Cl}$ ) absorveram quantidade de água menor do que aquelas submetidas ao teste normal (utilizando somente água) (Tabela 3 ), isto porque a solução salina controla a umidade relativa do ar, mantendo-a em torno de $76 \%$, como indica a literatura (Jianhua \& McDonald, 1996).

Os resultados dos testes de envelhecimento acelerado em solução salina ou água não apresentaram correlação significativa com a emergência de plântulas (Tabela 1), nem resultados coerentes na comparação entre médias (Tabela 2), ças nos teores de água entre os lotes de sementes, observados durante os testes.

\section{AGRADECIMENTOS}

À Sakata Seed Sudamerica LTDA, nas pessoas de Carlos Alberto Rodrigues da Silva, Celso Netto e Evelyn Fernandes de Araújo Koch, pelo fornecimento das sementes utilizadas nesse trabalho.

\section{REFERÊNCIAS}

BRASIL. Ministério da Agricultura e da Reforma Agrária. 1992. Regras para análise de sementes. Brasília: SNDA/DNDV/CLAV. 365p.

CARVALHO NM. 1994. O conceito de vigor em sementes. In: VIEIRA RD; CARVALHO NM. Testes de vigor em sementes. Jaboticabal: FUNEP. p. 1-30.

HAMPTON JG; TEKRONY DM. 1995. Accelerated aging test. In: Handbook of vigour tests methods. Zürich: International Seed Testing Association. p. 1-10.

JIANHUAZ; McDONALD MB. 1996. The saturated salt accelerated aging test for small-seeded crops. Seed Science and Technology 25: 123-131.

LOEFFLER TM; TEKRONY DM; EGLI BD. 1988. The bulk conductivity test as on indicator of soybean seed quality. Journal of Seed Technology 1: 37-53. provavelmente devido a estas diferen-
MARCOS FILHO J. 1999a. Teste de envelhecimento acelerado. In: KRZYZANOWSKI FC, VIEIRA RD; FRANÇA NETO JB. Vigor de sementes: conceitos e testes. Londrina: ABRATES. cap. 3, p. 1-24.

MARCOS FILHO J. 1999b. Testes de vigor: importância e utilização. In: KRZYZANOWSKI FC; VIEIRA RD; FRANÇA NETO JB. Vigor de sementes: conceitos e testes. Londrina: ABRATES. cap. 1, p. 1-21.

MARCOS FILHO J; SILVA WR; NOVEMBRE ADC; CHAMMA HMCP. 1990. Estudo comparativo de métodos para avaliação da qualidade fisiológica de sementes de soja, com ênfase ao teste de condutividade elétrica. Pesquisa Agropecuária Brasileira 25: 1805-1815.

MARTINS CC; MARTINELLI-SENEME A; CASTRO MM; NAKAGAWA J; CAVARIANI C. 2002. Comparação entre métodos para a avaliação do vigor de lotes de sementes de couve-brócolos (Brassica oleracea 1. var. italica plenk). Revista Brasileira de Sementes 24: 96-101.

McDONALD MB; WILSON DO. 1979. An assessment of the standardization of the ASA610 to rapidly predict potential and soybean germination. Journal of Seed Techonology 4: $1-11$

NASCIMENTO WM; BARROS BCG; PESSOA HBSV. 1993. Teste de envelhecimento acelerado em sementes de tomate. Revista Brasileira de Sementes 15: 251-253.

PANOBIANCO M; MARCOS FILHO J. 1998. Comparação entre métodos para avaliação da qualidade fisiológica de sementes de pimentão (Capsicum annuum L.). Revista Brasileira de Sementes 20: 306-310.

POWELL AA. 1995. The controlled deterioration test. In: VENTER HA. Seed Vigour Testing Seminar. Zürich: International Seed Testing Association. p. 73-87.

POWELL AA. 1986. Cell membranes seed leachate conductivity in relation to the quality of seed sowing. Journal of Seed Techonology 10: $81-100$.

RODO AB; TILLMANN MAA; VILLELA FA. 1998. Testes de vigor na avaliação da qualidade fisiológica de sementes de tomate. Revista Brasileira de Sementes 20: 23-28.

RODO AB; PANOBIANCO M; MARCOS FILHO J. 2000. Metodologia alternativa do teste de envelhecimento acelerado para sementes de cenoura. Scientia Agrícola 57: 289-292.

SÁ ME. 1999. Condutividade elétrica em sementes de tomate (Lycopersicum lycopersycum $L$.) Scientia Agrícola 56: 13-20.

SAKATA. 2002. Sakata Seed Sudamerica LTDA. Catálogo 2002: Tomate (Lycopersicum esculentum Mill.). 2p.

SALGADO JHH. 1996. Avaliação do vigor de sementes de milho (Zea mays L.) pela precocidade de emissão da raíz primária. Piracicaba: USP-ESALQ. 86p. (Tese doutorado).

SPÍNOLA MCM; CALIARI MF; MARTINS L; TESSARIOLI-NETO J. 1998. Comparação entre métodos para avaliação do vigor de sementes de cenoura. Revista Brasileira de Sementes 20: 301-305.

VIEIRA RD. 1994. Teste de condutividade elétrica. In: VIEIRA RD; CARVALHO NM. Testes de vigor em sementes. Jaboticabal: FUNEP. $\mathrm{p}$. 103-132. 